\title{
ARTÍCULO
}

\section{El derecho como dogma en la forma etico-politico liberal. Otra lectura desde el realismo critico de E. Mounier: la persona como fundamento ético de los derechos}

\section{Law as a Tenet in Liberalism. A New Reading from E. Mounier's Critical Realism: The Person as an Ethical Foundation of Rights}

\author{
Jose María Seco Martínez \\ Área de Filosofía del Derecho \\ Facultad de Derecho. Universidad Pablo Olavide de Sevilla
}

Fecha de recepción 28/06/2018 | De aceptación: 19/11/2018 | De publicación: 24/12/2018

\section{RESUMEN.}

El realismo crítico personalista plantea una nueva idea de juridicidad. Reclama frente a la escisión radical entre teoría y praxis jurídica, entre lo axiológico y lo normativo, entre la realidad y lo objetivo, que esgrime la argumentación kelseniana, una instancia crítica para el derecho positivo: la existencia de la persona humana concreta, (que hace y vive la historia), como fundamento inmediato de todo lo jurídico. Si partimos de la base de que siendo la teoría general del derecho una invención moderna, hasta su culminación en Kelsen, ¿por qué no admitir que pueda ser matizada por otros marcos axiológicos y cognitivos, también modernos, descuidados desde entonces por esa concepción normativista? Por eso, hablamos de "realismo crítico".

\section{PALABRAS CLAVE.}

Democracia, Modernidad, Capitalismo, Teoría General, Persona Humana, Derechos Humanos.

\section{ABSTRACT.}

The personalist critical realism sets out a new idea about legality facing Kelsen's argument. Kelsen claims a radical separation between legal theory and praxis, between the axiological and the normative, and between reality and objectivity. However, the personalist critical realism proposes a critical starting point: the existence of the real human being, the one who makes and lives history, as the immediate basis of the legal world. If we start from the assumption that the general theory of law is a modern invention, until it reached its highest point with Kelsen; why do not we admit that it can be elaborated by other cognitive frameworks, also modern, which have been ignored since then, by that normative idea? Therefore, we talk about "critical realism".

\section{KEY WORDS.}

Democracy, Modernity, Capitalism, General Theory of law, Human Being, Human Rights. 
Índice: 1. Prenotando: 2. Hegemonía liberal y el "desorden establecido". El dilema de la democracia.; 3. "(...) Y del derecho ha hecho la fortaleza de sus injusticias ". El "juridicismo" radical de la sociedad liberal: matriz del normativismo burgués; 4. A modo de conclusión: el "iusrealismo crítico" personalista. 5. Bibliografía.

\section{Prenotando.}

Emmanuel Mounier es un autor que crepita actualidad. Y lo es tanto por la riqueza de sus aportaciones, como por aquello que nos sugirió a través de sus escritos más señalados. Su obra está poblada de reflexiones muy audaces sobre la democracia y el derecho, que no hay que olvidar ${ }^{1}$. Precisamente aquí estriba su fuerza. El concepto de "desorden establecido"2 es un buen ejemplo de ello. Aún hoy puede seguir siendo de utilidad para el análisis jurídico-político. Pero, para eso necesitamos conocer de manera más diáfana qué nos quiso decir. A ello dedicaremos este trabajo ${ }^{3}$; a elucidar el peso que, en su historiografía, han tenido sus reflexiones acerca del estado de la democracia y el derecho. Algo que, a decir verdad, también ha sido muy común en pensadores de otros tiempos, pero que lo sitúan, a nuestro juicio, como uno de esos interlocutores con enfoques para precipitar un cambio paradigmático en la razón jurídica ${ }^{4}$.

Se nos podrá decir, y no sin razón, que el estado de la política y la experiencia contemporánea de las sociedades occidentales hoy no coinciden exactamente con las de su análisis. La reconfiguración paradigmática del sistema capitalista y la progresiva amortización del viejo diseño nacional-territorial, como fundamento político del Estado y de la ciudadanía, lleva las trazas de infringir cambios de relieve en la comprensión de la realidad política que, por aquél entonces, ya

\footnotetext{
${ }^{1}$ El personalismo es una filosofía y, en tanto que tal, también trasluce una filosofía del derecho. V. MOUNIER, E., El Personalismo, Madrid, Ed. Acción Cultural Cristiana, 1990, p. 3.

${ }^{2}$ Entendido este como ese "estado de injusticia institucionalizada por la legalidad" burguesa de la sociedad capitalista. Una categoría que transita a lo largo de toda su obra. V., por ejemplo, Id., Revolución Personalista y Comunitaria, en Obras Completas (en adelante Obras), Tomo I., Salamanca, Sígueme, 1992, pp. 359, 390, 401, 414, 434 y 471; Cfr. asimismo con Id., De la Propiedad Capitalista a la Propiedad Humana, en Obras, Tomo I., Op. Cit., pp. 599.

${ }^{3}$ Hay que decir también que esta investigación tropieza con el escaso conocimiento que todavía hoy se sigue teniendo del mismo. Se podría decir que su obra permanece, en cierta medida, oculta. Es muy difícil encontrar referencias de sus obras, no ya en cualquier compilación de pensamiento jurídico-político contemporáneo, sino en estudios más específicos sobre teoría política o filosofía jurídica

${ }^{4}$ Su filosofía es "algo más y algo menos que una filosofía", como bien ha apuntado P. RICOEUR, P., "Une philosophie personnaliste", en Esprit, $\mathrm{n}^{\circ} 174,1950$, p. 863. Más que una filosofía porque "introduce una inquietud, la que da lugar a una búsqueda". MELCHIORRE, V., "L`interpretazione di Cartessio nell penseiro di Mounier", Revista de Filosofía Neo-escolástica, $n^{\circ}$ 53, 1961, p. 300. Menos que una filosofia, si le exigimos que sea un sistema y si no obviamos el hecho de que su reflexión acerca de la política y el Estado, que florece en su haber, no es sistemática. Por eso, quienes se han acercado a su pensamiento coinciden en afirmar la importancia que en su sistema filosófico, adquirió todo lo relacionado con el estado de la política y la filosofía de la historia.
} 
hiciera este autor. El mundo es ahora sensiblemente distinto del panorama que diseñara el filósofo francés.

Claro que, no podemos pretender que sus esquemas conceptuales se adapten sin más a la realidad reciente. No podemos interpretar su pensamiento fuera de sus propios rieles históricos, so pena de ser anacrónicos. Un pensador es siempre rehén, para mal o para bien, del contexto en que históricamente le toca vivir. No hay que olvidar que los años en los que vivió podrían catalogarse de crisis paradigmática. Fueron años considerados de transición paradigmática de la modernidad occidental. Y en este contexto enfrenta algo, que hasta entonces era insólito en el panorama intelectual de las filosofías del irracionalismo: el análisis crítico de la democracia como "proceso histórico" de la modernidad. Por eso, es preciso atender a sus sugerencias, porque el estado espiritual de la época que le toco vivir, se puede definir también como de un profunda crisis o malestar; el fin de la "hegemonía europea sobre el mundo" . De ahí la necesidad de rearmar la gran tradición democrática 6 , pues, no en vano se apuntala como uno de los pilares esenciales de la cultura occidental. Para alguien como él, especialmente preocupado por el origen epistemológico de los problemas sociales, la democracia y, por tanto, el derecho tenían una dimensión emancipadora que debía indagarse.

Por eso, como pensamos que este autor pertenece a los clásicos, su obra nos ayuda a comprender y transformar el presente. Como se verá, su actitud fue rupturita con el ideología liberal dominante. Su filosofía, con un trabajo sistemático de años, se centro en la búsqueda de fundamentos filosóficos alternativos, para sustraer a la democracia de los rieles del liberalismo.

De ahí que podamos decir para empezar que su pensamiento, en este punto y en lo que aquí interesa, nos es bastante útil porque viene a elucidar la conexión entre derecho y democracia, como una relación fines-medios. El problema de la relación derecho-democracia, en la práctica, se transforma en un problema de "medios-fines” ¿Qué significaría la democracia, si el orden de los fines no influyera en

\footnotetext{
${ }^{5}$ V. LEFEBVRE, H. "Du culte de l'Esprit au matérialisme dialectique“, en Nouvelle Revue française, diciembre de 1932. Ya entre los años 1919 y 1922 Spengler publica su obra más famosa La decadencia de Occidente, que se situaría a la cabeza de una larga serie de obras y ensayos que tenían por objeto el estudio de la crisis. Este es el caso de obras tan significativas como Una nueva Edad Media de N. Berdiaeff; El fin de nuestro tiempo, de R. Guardini; La crisis de nuestra civilización, de H. Belloc, etc..., que formaban parte de lo que se ha dado en llamar "literatura de la crisis". Para una visión más específica y profunda del clima espiritual que se respiraba en aquellos años, cfr., MARITAIN, J., Carnet des notes, París, Desclée, 1965; y con GILSON, E., Il filosofo e la teologia, Brescia, Morcelliana, 1966.

${ }^{6}$ Ese será “el propósito esencial del filósofo personalista. No el de las pequeñas tradiciones democráticas". MOUNIER, E., Id., Revolución personalista y comunitaria, Op. cit., p. 335
} 
el orden de los medios, esto es, en el orden de su propio derecho? El fin sugiere siempre los medios. Si el poder reside en el fin, también lo encontraremos en los métodos. Por eso, si el derecho no es un fin en sí mismo, sino que es útil a la consecución de fines - lo que le confiere ese carácter pragmático que tanto lo define y que se sintetiza en la idea de operatividad ${ }^{7}$-, no cabe otra cosa que admitir su carácter dinámico $\mathrm{y}$, por tanto, histórico e inserto en el mundo que viven y constituyen los seres humanos. El derecho no tiene realidad sustancial, pese a los afanes del iusnaturalismo. Sí, claro que se constituye de manera sustantiva, pero como experiencia jurídica. Luego, siendo esto así, es posible pensar el derecho de otra forma, esto es, re-situando al ser humano ${ }^{8}$, que hace (y vive) la historia, como la referencia ética básica; como el fundamento inmediato de todo el fenómeno jurídico, frente - también -, a la escisión radical entre la teoría y la praxis jurídica, entre lo axiológico y lo normativo, entre la realidad y lo objetivo, que propone la argumentación kelseniana.

\section{Hegemonía liberal y el "desorden establecido". El dilema de la democracia}

Si la democracia, como proyecto histórico, siempre se ha significado en el campo político por la búsqueda de la justicia social y por la distribución del poder entre las personas, el análisis de E. Mounier dista bastante de solidarizarse con la defensa de la democracia liberal y parlamentaria, si bien refrenda la necesidad de asumir las conquistas y los principios que propiciara como democracia moderna. Pero no como el gran objetivo a batir, sino como el punto de partida de un proceso más extenso. Para la filosofía personalista no se trata de remozarlo todo, sino de profundizar en el autogobierno y en la recuperación de espacios comunes.

Esto explicaría la insistencia de nuestro filósofo en elucidar las contradicciones que los sistemas democráticos liberales o representativos han infringido al autogobierno ciudadano y a la idea de comunidad de intereses. Desde la antigüedad clásica, el vigor de la política, como expresión histórica de las soluciones a los problemas de la convivencia, ha sido siempre sinónimo de compromiso social. Pocos autores de los siglos XVII y XVIII dejaban de incorporar una Política a su Teodicea, a su Lógica o a sus Tratados ${ }^{9}$. Sin embargo, este hecho contrasta hoy con el escepticismo y con el desprestigio de la

\footnotetext{
${ }^{7}$ No en vano "la actividad del jurista está dirigida no al simple conocer, sino al conocer para actuar". ORESTANO, R., Introducción al estudio del derecho romano, Madrid, Universidad Carlos III de Madrid-BOE, 1997, p. 364

${ }^{8}$ V. MOUNIER. E., Manifiesto al servicio del personalismo, en Obras Completas, Tomo I., Op. Cit., pp. 634-636.

${ }^{9}$ V. Ibid, p. 717.
} 
vida pública de nuestras democracias. Por eso, no basta con explorar nuevas ideas, más allá de la rigidez conceptual de los marcos pre-políticos tradicionales; se necesita también rastrear, para luego restaurar, el carácter emancipador de nuestras tradiciones democráticas.

El dilema para nuestro pensador estaba claro: había que optar entre la democracia burguesa cosmopolita (o liberal) y la democracia popular (o participativa). Desde esta perspectiva, la democracia representativa no es más que una concepción incompleta de democracia, que "despierta un inmenso desengaño". Aún así, constituye el punto de partida desde el que “orientarnos en dirección a una democracia verdadera". Pero si no lo hacemos, "madurará en ella - como bien escribe - un nuevo fascismo" ${ }^{10}$. La democracia liberal, "desde esta perspectiva, es ya fascismo, pues lo prepara (...). Por eso, es preciso combatirla con inmediatez (...)"11.

Es cierto que la democracia representativa es la concepción de democracia que se ha globalizado merced a la liberalización política, pero también lo es que, en realidad, se trata de una concepción instrumental que pretende estabilizar la liberalización económica e impedir el deterioro de las instituciones frente a los efectos del capitalismo. El consenso liberal presupone la compatibilidad entre la liberalización económica y la política. No en vano, desde los orígenes de la democracia liberal representativa, elecciones libres y mercados libres siempre se han considerado las dos caras del liberalismo.

Aquí precisamente reside la diferencia entre ambas: en la negación de esa pretendida compatibilidad entre democracia y capitalismo. La idea cognitiva básica de la democracia personalista es que el capitalismo infringe un daño sistemático a la mayoría de las personas. Desde esta perspectiva la "democracia capitalista" es una contradicción en sí misma. Y si hablamos de "contradicción" es porque el capitalismo ${ }^{12}$, como modelo de producción - ya hegemónico -, no parece que fuese una consecuencia sin más de la modernidad, entre otras cosas, porque la modernidad no presuponía en

\footnotetext{
10 “ (...) Toda timidez al respecto debe ser denunciada como proveedora de fascismo”. Id., Réponse a l'Enquête philosophique sur les conflits actuels d'ideologies. (Texto original mecanografiado), UNESCO PHS/W/68z), 1949, pp. 1-2

${ }^{11}$ Incluso, llegado el caso, desde la resistencia activa violenta e ilegal y/o revolución. Algo que los revolucionarios cristianos habrían de plantearse "siempre y cuando concurra la aparición de ciertas condiciones esgrimidas también por los teólogos (desde Sto. Tomás y Suárez a Lehmkuhl, P. Cathrein y Castelein)” (....)” Id., Revolución Personalista y Comunitaria, Op. cit., p. 427.

12 No en vano el capitalismo representaba, para nuestro autor, un sistema moralmente indiferente de su definición teórica, el principal agente de opresión de la persona humana en el curso en la historia. Id., Manifiesto al servicio del personalismo, Op. Cit., pp. 591 et sequens
} 
absoluto el capitalismo ${ }^{13}$. Antes al contrario, este se impuso - como modo de producción y reproducción social - a los procesos socio-culturales e históricos de formación de la modernidad, ocultándolos y subsumiéndolos a los esquemas de la dominación burguesa capitalista. "La democracia capitalista - escribe Mounier - es una democracia que da al hombre libertades que el capitalismo luego le impide usar"14.

Por eso, la democracia personalista, léase participativa, es menos procedimental, pero más sustantiva que aquella. Se centra mucho más en la distribución del poder y en la búsqueda de la justicia social, que en la idea de gobernabilidad ${ }^{15}$. Al cabo, los valores políticos asociados a los procesos modernos de democratización de la sociedad - la libertad, el pluralismo social, el politeísmo de valores, la igualdad -, abandonan su sentido más instrumental y adquieren un índice más enérgico al abrigo de la idea de participación común. La verdadera democracia, en consecuencia, es antagonista del capitalismo, porque sólo desde la realidad desnuda e inmediata de las personas, desde la historicidad (finitud) de sus condiciones sociales, se puede construir la igualdad real (efectiva) de todas las personas. La democracia nos enseña y, como no, nos exige actuar y pensar en común, desde y para todos los sujetos.

En fin, para nuestro autor, la democracia liberal resultó ser, ni más ni menos, que el espejo de un orden socio-económico específico, el burgués, en busca no ya del poder político, sino del asentamiento de las bases del desarrollo capitalista de la historia, mediante la transformación jurídica y, por tanto, sociopolítica del orden existente. La sociedad burguesa pivotaba sobre dos acuerdos universales: (i) uno sobre la ciencia, es decir, sobre "un pensamiento impersonal válido para todos", una especie de racionalismo absoluto; y otro (ii) "sobre el acuerdo de las conductas en un orden jurídico formal"16, esto es, sobre su propia juridicidad. De este modo se aseguraba el control de las

\footnotetext{
${ }^{13}$ Esta línea es sostenida por el sociólogo portugués Boaventura de Sousa Santos "La modernidad no presuponía el capitalismo como modo propio de producción. En verdad, concebido como modo de producción, el socialismo marxista es también, al igual que el capitalismo, parte constitutiva de la modernidad" SOUSA, B., Crítica de la razón indolente. Contra el desperdicio de la experiencia, Bilbao, Desclée de Brouwer, 2003, p. 51. Pero, el hecho es que convergieron. V. asimismo a Ferrajoli, L , Derecho y razón. Teoría del garantismo penal, Madrid, Trotta, 1995.

${ }^{14}$ MOUNIER. E., Revolución personalista y comunitaria, Op. cit., pp. 335 y 336. Así es, "La libertad capitalista ha entregado a la democracia liberal, utilizando las mismas armas y fórmulas que le daba, a la oligarquía de los ricos (oligarquía de poder y de clase); luego, en una última fase, a un estatismo controlado por la gran banca y la gran industria, que no solamente se han apoderado de los mandos ocultos del organismo político, sino de la prensa, de la opinión, de la cultura, a veces incluso de los representantes espirituales para dictar las voluntades de una clase o modelar las aspiraciones, sin dejar de vedarles los medios de realizarlas". Ibídem
}

${ }^{15}$ SOUSA, B., Sociología Jurídica Crítica. Para un nuevo sentido común en el derecho, Madrid, Trotta, 2009., p. 497.

${ }^{16}$ MOUNIER, E., El Personalismo, Op. cit., p. 25. 
condiciones que harían posible su hegemonía, y, a su vez, se embozaba "la injusticia permanente de apariencia legal" que aparejaba, esto es, su propia dominación ${ }^{17}$, por medio de la adopción de la razón (burguesa) como principio que explica la historia ${ }^{18}$. La comprensión de la historia - que ahora es la suya - se piensa como res cogitans. Se trataba de eso, de sepultar el viejo orden, afianzando sus propias concepciones normativas acerca de la justicia y la humanidad - una suerte de absolutismo ético- ${ }^{19}$ a través del positivismo científico como ideología y del juridicismo formal ${ }^{20}$.

Por tanto, llegados a este punto y con el ánimo de sintetizar, cabe una pausa para dejar en reposo las siguientes ideas:

i) El modelo liberal de sociedad se sustentaba merced a un compromiso con la racionalidad que terminó con la aceptación de la razón como principio universal, que corregía el caos de las sociedades irracionales, controlaba a la naturaleza y explicaba sus fenómenos a través del principio de causalidad. Se trataba, sin ninguna duda, de "una sociedad de inteligencias"21. Claro que la nueva ciencia y su ideología condujo a la propia reflexión jurídica a aceptar un orden de cosas en el que el positivismo constituía la única vía divisable para escapar de las sociedades del antiguo régimen. Esto explicaría la dependencia cada vez mayor de la reflexión jurídica del ideal instrumental de la ciencia, que le auguraba una racionalidad definitivamente emancipada de la metafísica. Se daba paso así a "una ciencia del derecho" que ya se pensaba a concebir como "sistema de ciencia", en la medida en que era capaz de auto-producirse y de repetirse de acuerdo con un esquema causal y auto-referente. Un

\footnotetext{
${ }^{17}$ Id., Revolución Personalista y Comunitaria, Op. Cit., p. 233.

${ }^{18}$ Id., Manifiesto al servicio del personalismo, Op. cit., p. 797. V. Ibáñez, P., Justicia/Conflicto, Madrid, Tecnos, 1988, p.47.

19 El racionalismo absoluto es el fundamento, como bien apunta Oscar Correas, al hilo de cuanto aquí se dice: "del iusnaturalismo intolerante, de ese pensamiento ético que cree que lo bueno es lo mismo que lo verdadero, y que quien tiene la verdad, que nadie le ha reconocido por lo demás, tiene también el derecho a mandar. Este racionalismo absoluto genera lo que se denomina absolutismo ético. Su fundamento está en la concepción según la cual todo tiene un logos, un orden y la violación de ese orden es lo malo, lo que debe ser reprimido." CORREAS, O., Metodología jurídica. Una introducción filosófica I, México, Fontanamara, 1997., p. 65

${ }^{20}$ Así las cosas con la ciencia, el contrato social y el derecho se quiso creer que se marchaba hacia horizontes inéditos de paz universal. Es más, se llegó a condicionar la conquista de la "felicidad política", del reconocimiento (por supuesto no a todos los sujetos) de los derechos que el nuevo modelo de sociedad política necesitaba para su funcionamiento (derechos naturales e inalienables). Id., El Personalismo, Op. cit., p. 25 Lo que rubricaría la tesis de que lo jurídico se seguía resistiendo a abandonar su fundamento natural. V. a GAUTHIER, F., Triomphe et mort du droit naturel en Révolution, 1789, 1795, 1802, Paris, PUF, 1992.

${ }^{21}$ MOUNIER, E., Manifiesto al servicio del personalismo, Op. cit., p. 640. En ella rige un pensamiento impersonal, como única vía posible de lo real, que pretendiendo la unanimidad de los individuos y la paz entre las naciones, acabó por esclerotizar la riqueza de la persona humana, reconduciéndola a puros esquemas, donde el hic y el nunc de la percepción inmediata, la realidad subjetiva, son simplemente substituidas por un modo impersonal de puros objetos y de puras funciones.
} 
planteamiento que se ha depurado hasta el extremo en la idea kelseniana de que el Derecho rige su propia producción ${ }^{22}$.

ii) Pero, en el (modelo ético-politico liberal) que también se procedía a la sustitución del zoom politikon de Aristóteles por otro vinculo social como fundamento absoluto del sistema marco de la modernidad: el "individuo" como sujeto abstracto, descarnado y abstraído completamente de su propio pasado, al pretenderse universal. La teoría contractualista, que funda la democracia liberal, pivota sobre un modelo tan hipotético y abstracto, como descontextualizado y ficticio, de individuos libres, independientes e iguales por naturaleza, que deciden ponerse de acuerdo y ceder algunos derechos para salvaguardar la propiedad y la vida. Con esto no es que se quiera desmerecer la importancia histórica del contractualismo como sostén del individualismo moderno. Más bien lo que se viene a reprochar aquí a la democracia liberal, amén del alejamiento representativo de sus propias instituciones:

a) es que haya entregado conceptos como el de interés público, comunidad o gobierno a la reproducción socio-económica liberal. Es decir, se pretende recriminar su perfil instrumentalista que supedita el interés común a las necesidades privadas e individuales, o más concretamente y desde nuestro punto de vista, a los derechos de propiedad concebidos por el contractualismo. Lo cual no nos debe sorprender cuando en el fondo, bajo la búsqueda nominal de la libertad, el contractualismo actuaba sobre las instituciones y las relaciones sociales en orden a la instauración definitiva (léase jurídica y ética) de los pilares sobre los que se apuntalaba el liberalismo burgués: libertad, propiedad, seguridad y cumplimiento de los contratos. De este modo, participación y comunidad quedaban a expensas del individualismo.

b) Y que, en lo que al derecho moderno se refiere, haya propiciado el desplazamiento secuencial en la figura del sujeto: del hombre (la razón es ya patriarcal relegando así a la mitad del mundo) al ciudadano, que es el buen burgués, y de éste a la persona jurídica, como centro de imputación de

\footnotetext{
${ }^{22}$ Id., E., El Personalismo, Op. cit., pp. 24 a 26, 51 y 73 a 74. V. a KELSEN, H., Teoría pura del Derecho, México, UNAM, 1979. El derecho sería comparable a un mecanismo cibernético, en la medida en que pese a ser un sistema mecanizado se le habría transferido la inteligencia como para funcionar con autonomía y evolucionar de manera programada con arreglo a tiempos cuidadosamente calculados. V. en este sentido a TRIGAUD, J.M., Le droit et le futur, Paris, P.U.F., 1985, p. 65 y Persona ou la justice au double visage, Genova, Studio Editoriale di Cultura, 1990, p. 75.
} 
derechos y deberes o con capacidad para formalizar contratos ${ }^{23}$. Lo que cualificaba para ser sujeto de derecho no era su condición de (ser) humano, sino su posición respecto de los medios de producción.

iii) Por otra parte, irrumpe el concepto de Nación - reflejo idealista de la burguesía como clase -, como la unidad política fundamental, que vertebraba todo el sistema político, encauzaba el ejercicio de los derechos y aseguraba la lealtad social. La burguesía se llamará a partir de ahora Pueblo, Nación, Patria. La nación será su conciencia de clase $^{24}$, una representación colectiva e indisoluble de sí misma constituida en el Estado. Su voluntad será la voluntad general, una voluntad casi metafísica que descarta "las divisiones, las escisiones, las minorías y maldice (...) todo lo que pueda compartir su voluntad, (...) todo lo que pueda crear en ella diversidad, pluralismo, divergencia". ${ }^{25}$ En el tránsito a la modernidad y bajo el decorado de declaraciones y cambios socio-culturales nada había cambiado. Se seguía manteniendo la misma concepción dogmática del poder. Ahora era la nación, como reflejo objetivo e intemporal de la voluntad general, esto es, de la burguesía como grupo social hegemónico, la que tomaba las prerrogativas del rey, como antes éste las había asumido del Sumo Pontífice ${ }^{26}$. La secuencia de absolutización del poder había permanecido intacta.

iv) Así las cosas, la idea de individuo como fundamento absoluto, merced a la ficción idealista de la autonomía de la voluntad - el auténtico distintivo del individualismo burgués - y la idea de nación como entidad metafísica, como base natural del Estado - no como uno de sus elementos constitutivos ${ }^{27}$ -, aforaron una nueva manera de configurar el mundo, por medio de su propia juridicidad. La sociedad liberal, pese a la democracia representativa, devenía así en una especie de "desorden establecido" de

\footnotetext{
${ }^{23}$ V. MOUNIER, E., Revolución Personalista y Comunitaria, Op. Cit., p. 233

${ }^{24}$ Veamos sino como escribe el propio Mounier: “¿acaso fue para oponer una fuerza mística igual a la del poder absoluto de derecho divino de los reyes, para lo que los primeros teóricos de la democracia construyeron esta imagen simétrica del poder divino de los pueblos, absoluto e infalible como el de los reyes? Ya no es preciso hacer la crítica de este mito, lo que no le impide que siga vivo. (...) ¿Qué es el 'pueblo'? ¿El conjunto del pueblo? Pero el pueblo no se expresa más que a través de las democracias directas, que se han convertido en un imposible al constituirse las grandes naciones. ¿Es el sector del pueblo, y esta parte de su voluntad, los que intervienen activamente en el poder? Pero ¿Qué representan?” Id., E., Manifiesto al servicio del personalismo, Op. cit., p. 726.

${ }^{25}$ Es más, su visión de la "colectividad es indivisa; su sufragio universal es indiviso, de donde surge una asamblea unitaria que segrega a su vez un gobierno indiviso, que produce una nación también indivisa: todo el jacobinismo, todo el sistema de centralización, de imperialismo, de absolutismo, proviene de esta forma de idealismo popular”. Id., E., Anarquía y personalismo, Op. cit., p. 799. V. también a PALMER, R., The Improvement of Humanity, Education and the French Revolution, Princeton, Princeton University Press, 1985.

${ }^{26}$ V. a Kantorowicz, E., "Mysteries of State: An Absolutist Concept and his Late Medieval Origins", en Harvard Theological Review, 48, 1955, p. 88

${ }^{27}$ La nación entendida como colectividad orgánica no es uno de los elementos que constituyen el Estado, sino el elemento por el que este se constituye, entre otras cosas porque se identifica con él.
} 
apariencia legal y sostenido por la fuerza, que había declinado cumplir con sus promesas de emancipación ${ }^{28}$, que fueron supeditadas en nombre de esa razón de estado y conforme a la lógica del capital, para restringir el concurso de aquéllas otras emancipaciones de la modernidad, que pugnaban por salir y ganar el lugar ocupado por la burguesía. Seguía operando el mismo modo absoluto de entender la realidad.

En definitiva, la democracia liberal y el derecho moderno ${ }^{29}$ sintetizaban, por tanto, la confluencia entre las exigencias del modo burgués de producción capitalista y los procesos de la modernidad occidental (secularización y democratización), vinculados a a la idea de felicidad política por medio de la razón (racionalismo laico). Empero, la verdadera democracia es aquélla que descansa o se identifica, no con la mística de las mayorías ${ }^{30}$, sino con la fuerza del derecho, en su vertiente emancipadora. No es este el caso del derecho moderno, donde ha triunfado, como se verá más adelante, la regulación sobre la emancipación. El derecho moderno representaba, ni más ni menos, que la naturalización de ese “desorden establecido” por la legalidad burguesa, que niega el bien común y es funcional al ocultamiento de su propia dominación (injusticia institucionalizada) ${ }^{31}$, por medio de la confianza demiúrgica en una razón que guía la historia, la razón liberal. Por tanto, y en lo que aquí interesa, que la irrupción del capitalismo en la modernidad haya propiciado una reducción regulatoria del derecho, como veremos a continuación, es precisamente el resultado de la apropiación que de la modernidad ha hecho el capitalismo. Pero este hecho, producido ya, no presupone que fuera inevitable. Este es uno de los puntos de partida de la filosofía personalista.

\footnotetext{
${ }^{28}$ La despersonalización - escribe Mounier - del mundo moderno y la decadencia de la idea comunitaria constituyen una sola y misma disgregación. V. MOUNIER, E., Manifiesto al servicio del personalismo, Op. Cit., pp. 618-620.

${ }^{29}$ MOUNIER, E., Revolución personalista y comunitaria, Op. cit., p. 334. Cfr. también con LACROIX, J., "La démocratie et la souveranité du droit", en Esprit, No 30, Marzo de 1935; y en Ordre Nouveau, no 31, Junio de 1936.

${ }^{30}$ MOUNIER, E., Anarquía y personalismo, Op. cit., p. 799. También en Id., Revolución personalista y comunitaria, Op, cit., p. 333 y en Id., "Réponse à l'Enquete philosophique sur les conflits actuels d' ideologies", en Op. cit., pp. 2 y 3 . En fin, el absolutismo mayoritario no es más racional que la arbitrariedad de uno sólo. Como tampoco representa la felicidad de los pueblos. "Los fascismos pueden asegurarla también materialmente e incluso subjetivamente, en un pueblo cansado y privado de libertad" 30 . Id, Manifiesto al servicio del personalismo, Op. cit., p. 729.

31 "Una legalidad que perpetua el desorden, una legalidad ciertamente injusta, que, como escribe Mounier, recubre la injusticia permanente con una apariencia legal” Id., Revolución Personalista y comunitaria, Op. Cit., p. 233. V. asimismo la nota 2.
} 


\section{3. " (....) Y del derecho ha hecho la fortaleza de sus injusticias" ${ }^{932}$. El "juridicismo" radical de la sociedad liberal: matriz del normativismo burgúes.}

Por tanto, como ya se ha visto, los procesos de secularización de la realidad propiciaron, nada menos, que el descubrimiento de la reflexión jurídica como ciencia del derecho. Su modo de conocer será el de la ciencia moderna (funcionalismo e instrumentalismo) con sus ideales de uniformidad, control, regularidad y previsibilidad. Y su ideología será el positivismo como expresión filosófica y científica "del buen orden racional", frente al caos de las sociedades pre-modernas.

Pero frente a este hecho las sospechas de nuestro autor apuntaban en la siguiente dirección:

i) De la misma forma que para las ciencias de la naturaleza sólo existía un tipo de realidad: la que ha sido pensada de manera objetiva ${ }^{33}$, la ciencia del derecho reivindicaba para sí la realidad del derecho, haciendo de él un sistema auto-poiético. Ahora su única divisa consistirá en su realización como sistema impermeable a la exterioridad. Su fuerza reside, precisamente, en esa representación a priori de la realidad a la que pretende precisamente regular. El derecho deviene así en un sistema cerrado y autónomo, pero con capacidad para imponerse de manera universal como una necesidad lógica y normativa, al tiempo que se desnuda de su densidad real ${ }^{34}$. El derecho, ahora compuesto de hechos normativos y unificados por un cuerpo de doctrina, se neutraliza (se auto-exime de cualquier juicio ético) y se absolutiza como saber propio con capacidad para captar acepciones válidas de la realidad ${ }^{35}$

\footnotetext{
${ }^{32}$ Id.,, Manifiesto al Servicio del Personalismo, Op. Cit., p. 594

${ }^{33}$ Una realidad de representaciones y de conceptos que prescinde de lo concreto. Una realidad donde la sistematización y el razonamiento identifican la realidad humana total con el objeto científico. Una realidad, como bien dijera Marcel, "deshumanizada y despojada de significaciones y valores". De ahí que "el mundo del racionalismo sea de una abrumadora tristeza" MARCEL, G., Positions et approches concrètes du mystère ontologique, Desclée de Brouwer, Paris, 1935, p. 258.

${ }^{34}$ Boaventura de Sousa Santos nos lo sintetiza, en lo que interesa aquí, de una manera bastante diáfana: "(...)la ciencia de la sociedad tiene por objeto la sociedad como debiera ser. (...) el hiato que existe entre el ser y el deber ser puede determinarse científicamente (las leyes de la evolución social), pero, por lo menos por el momento, no puede ser rellenado recurriendo solamente a la ciencia. Es necesario un acto de voluntad que, sin embargo, puede ser creado científicamente. El derecho moderno es ese acto de voluntad y el agente de esa voluntad es el Estado". SOUSA, B., Crítica de la razón indolente. Contra el desperdicio de la experiencia, Op. cit., p. 159.

${ }^{35}$ A este proceso de absolutización como saber independiente, propio de los racionalismos, lo expresó Jaspers de manera muy precisa: " Se espera erróneamente del intelecto la certeza de todo aquello que es decisivo para la vida" y es que "a lo preciso, pero finito,(...) se le da el valor absoluto del todo". JASPERS, K., La Filosofía desde el punto de vista de la existencia, México, FCE, 1953 , p. 77.
} 
ii) Claro que siendo esto así, (el derecho moderno es ya unívoco y universal, metódico y predicativo), es lógico pensar que este acabase abdicando de la realidad. Y así fue. La dialéctica realidad-derecho se allana a la realidad objetiva del derecho, autónoma e impermeable a la contingencia cotidiana de los seres humanos, "ciega al misterio de sus existencias reales" 36 . La realidad jurídica es ahora distinta y se mantiene al margen de la existencia real de los sujetos. Mediante sus conceptos, sus institutos y sus categorías va configurando otra realidad: la jurídica; que, a su vez, prefigura, con arreglo sus esquemas conceptuales, las relaciones sociales que pretende regular.

La objetividad de la ciencia jurídica no sugiere otra cosa que indiferencia social, pues extrae al sujeto de su entorno existencial, de su entramado más inmediato de intereses vitales, al tiempo que se encarga de hacer el mundo social en el que este se inserta. El fin de la reflexión jurídica, por tanto, ya no será la contingencia "como condición humana de la modernidad"37; ya no será el ser humano concreto con sus singularidades irrepetibles. Antes al contrario, se olvida de este y lo separa de la existencia. Los filósofos y los juristas "se han dedicado a 'desarrollar el mundo como un sistema de puras esencias, esto es, de meros posibles, por lo que resultaba indiferente que existieran'. (....) creyeron que todo podía ser reducido a un sistema"38.

iii) Dicho esto, lo que venimos a insistir aquí es en el acierto de la filosofía personalista a la hora, no ya de ubicar a la reflexión jurídica entre las - como el mismo denominaba "mediaciones racionales" constituidas por la razón objetiva, siempre ajenas "al sentido carnal del mundo o a la camaradería de las cosas"39; ni tan siquiera la de resaltar la importancia de lo jurídico dentro del liberalismo, que es un hecho contrastado, cuanto la de elucidar que el Derecho así entendido se erigiera en la mejor opción para aderezar primero y acelerar después el cambio social que la sociedad burguesa requería.

Claro que, debido a estas sospechas no es difícil concluir que, para nuestro autor, el Derecho fuera considerado por el programa revolucionario del liberalismo, como el punto de partida de lo que

\footnotetext{
${ }^{36}$ MOUNIER, E., Manifiesto al servicio del Personalismo, Op. cit., p. 596

${ }^{37}$ HELLER, A., Una Filosofía de la Historia en fragmentos, Barcelona, Gedisa, 1999, p. 32.

38 "Ahora bien, contra esa pretensión se alza la profunda negativa de Kierkegard cuando afirma que no cabe un sistema de la existencia" CANDIDE, M., El pensamiento de Emmanuel Mounier, Ediciones Estela, Barcelona, 1969, p. 188. V. HEGEL, G.W.F., Fundamentos de la Filosofia del Derecho, Siglo Veinte, Buenos Aires, 1987, pp. 231 y ss.
}

${ }^{39}$ MOUNIER, E., Revolución personalista y Comunitaria, Op. Cit., p. 183. 
hasta entonces no había sido posible: que la burguesía, como grupo social, tomara la historia, para luego hegemonizarla, mediante la creación de su propio estatuto jurídico. El derecho común, dinámico y convencional, vinculado a la historia del derecho europeo desde el siglo XI, ya no era funcional a sus reivindicaciones como clase social. No satisfacía sus expectativas de regulación automática del orden social y de los procesos económicos, pese a que siempre había contribuido, merced al trabajo de glosadores y comentaristas del Corpus Iuris Civilis, a blindar sus aspiraciones socio-económicas.

En la época del Usus Modernus Pandectarum y frente a la expansión de los iura propria de las monarquías absolutas, el ius commune había servido para preservar intactas sus expectativas de entrar en la historia. Pero, ahora que lo había conseguido, necesitaba crear su propio modelo de sociedad jurídica. De este modo, se aseguraba no ya sólo su primacía política y económica, sino la reproducción de su propio marco categorial, asegurándose, en todo momento, el control de los cambios que aparejaba el progreso de la economía ${ }^{40}$. A raíz de entonces la reflexión jurídica se convierte en el ariete que la sociedad liberal necesitaba para operar sobre la realidad. El derecho asumía, por un lado, la misión de diseñar la vida social de acuerdo con las tesis del contractualismo, como concepción normativa universal; y, por otra, la función de legitimar el poder del Estado, como reflejo de esa idea objetiva y atemporal de la soberanía nacional ${ }^{41}$, en un contexto de transición paradigmática que identificaba modernidad con capitalismo y ciencia con derecho. Pero el derecho - que ya es razón jurídica merced a la racionalidad cognitivo-instrumental que había tomado de las ciencias naturales -, lejos de poder controlar al Estado, acabo siendo instrumentalizado por este, hasta que se confundió con él. La dominación política como dominación técnico jurídica estaba servida. El Estado se juridifica y se racionaliza. Y el derecho se configura como su "objetivación más fuerte y concentrada"42, merced a su reducción a la ley (universal y abstracta), por aquél legislada, como única fuente de producción del derecho. El derecho se erige así en un mecanismo decisivo de regulación social e institucional. Se deslegitima así su potencial emancipador y comienza a esbozarse la sociedad capitalista.

\footnotetext{
${ }^{40} \mathrm{~V}$., en este sentido, a MONEREO, J.L., "La organización jurídico-económica del capitalismo moderno: El derecho a la economía. Estudio Preliminar”, en RIPERT, G., Aspectos jurídicos del capitalismo moderno, Granada, Comares, 2001, p. 21.

${ }^{41}$ Cfr. LEGENDRE, P., El amor del censor. Ensayo sobre el orden dogmático, Barcelona, Anagrama, 1979, pp. 218 ss.

${ }^{42}$ MOUNIER, E., El Personalismo, Op. cit., p. 73. No existía mejor modo de programar el cambio, de cristalizar, en un nuevo orden a medida, el proyecto social y político que venía requiriendo esta nueva clase social prácticamente desde el humanismo renacentista. ¿O acaso existía un modo mejor de naturalizar el proceso histórico, de supeditar el progreso histórico al desarrollo del capitalismo? ¿Existía mejor forma de ocultar, bajo el compás revolucionario, lo que no era más que tomar - que no transformar - el poder?
} 
La gran agudeza de Mounier, en este punto fue, por tanto, la de intuir que el derecho moderno ha sido, ni más ni menos, que un instrumento de dominación en manos del capitalismo. O lo que es lo mismo, su propio derecho. De ahí su radical juridicismo ${ }^{43}$. Al fin y al cabo, no había hecho otra cosa que afianzar jurídicamente, con sus construcciones categoriales, la reutilización de los viejos institutos clásicos y la proscripción de la interpretación, las transformaciones que el sistema capitalista como proceso histórico necesitaba. ¿De qué otra forma si no se hubiese deslizado mejor el capitalismo, que programando jurídicamente los cambios que necesitaba el funcionamiento de la empresa capitalista?

\section{A modo de conclusión: El "iusrealismo crítico" personalista}

Llegados a este punto y para lo que nos interesa aquí, partiendo de la base de que jurídicamente no se acaba de dar una respuesta satisfactoria a los derechos de la persona (léase humanos, en su sentido más germinal), pretendemos deletrear aquí algunas de las vías esbozadas por nuestro autor. Ni que decir tiene que con este trabajo lo que se ha buscado es solo una aproximación propedéutica, desde su pensamiento, a la discusión de por qué el derecho positivo, pese a su secular búsqueda de sistematización y racionalización, no les ha dado cobijo; por qué han sido siempre considerados por la razón jurídica como un referente extraño (extrajurídico); por qué se sustentan sobre esa idea de universalidad centrada en el olvido de la persona ${ }^{44}$. Cómo es lógico, tratándose de una aproximación cuanto aquí se apunta como perspectiva habrá de desarrollarse más adelante.

La filosofía personalista orienta sus reflexiones hacia una nueva juridicidad, a través de una concepción diferente de normatividad. Por lo pronto, se sustrae a ese dualismo ontológico entre derecho natural y derecho positivo. En la raíz de la inteligencia (jurídica) debe haber, parafraseando a Marcel, "una toma sobre lo real". ${ }^{45}$ Por eso reclama una instancia crítica (ética necesaria) para el derecho positivo: la existencia de la persona humana concreta como juicio ético necesario, es decir, como fundamento inmediato de "existencia" de la persona humana en tanto que sujeto ético. Quien profiere ese juicio de existencia es siempre la persona individual, el sujeto humano vivo con necesidades $^{46}$, desde su propia contingencia humana e histórica. Este "derecho vivo" 47 - tal y como lo

\footnotetext{
${ }^{43}$ MOUNIER, E., Manifiesto al servicio del personalismo, op. cit., p. 594.

${ }^{44}$ Ibid., Op. cit., p. 25.

${ }^{45}$ MARCEL, G., Ser y tener, Madrid, Caparrós Editores, 1996, p. 54

${ }^{46}$ MOUNIER, E., Manifiesto al servicio del personalismo, Op. Cit., p. 136
} 
refiere nuestro autor - no deriva de ninguna instancia trascendental, ni incurre en absolutizaciones dogmáticas. Lo cual equivale a decir, en lo que aquí buscamos, que los derechos de la persona (léase humanos) no se pueden "pensar" estrictamente en términos de norma jurídica, esto es, sin superar el paradigma normativista

Siendo este el caso, el problema de deber ser del derecho no estriba - desde esta perspectiva en la sustitución sin más de la norma como categoría decisiva de la razón jurídica, sino en orientar la fuerza (distintivo de lo jurídico) a los reclamos de una ética (necesaria) decididamente común. Si lo jurídico no es más que el producto necesario de la fuerza, su principal distintivo (pues no parece que pueda sustraerse a ese carácter coercitivo); si la fuerza "es uno de sus principales atributos" 48 , - el derecho sólo será posible si nace de una lucha de fuerzas, si expresa una relación de fuerzas, si vive sostenido por una fuerza. Y es aquí, donde la filosofía de Mounier añade el matiz esencial que sintetiza toda su concepción de lo jurídico como fenómeno humano: el derecho es algo más que el producto necesario de la fuerza, es "un ensayo precario de racionalizar la fuerza e inclinarla al campo del amor"49, como expresión de su dimensión emancipatoria (su cara utópica), frente a la mirada regulatoria que aparece, por ejemplo, en Kelsen, para quien lo jurídico nada tiene que ver con la conducta fáctica de los hombres, sino con el orden constituido por un conjunto de reglas que determinan como deben comportarse en relación a los demás ${ }^{50}$.

La relación fuerza-derecho, deviene, por tanto, en una relación necesaria para el fortalecimiento de un orden justo; no como una forma de sometimiento al poder, sino como una tensión necesaria para fortalecer la justicia. Lo cual equivale a decir que los derechos de la persona (léase humanos) no se pueden "pensar" estrictamente en términos normativos. Es preciso ir más allá del paradigma normativista. Es preciso situar al ser humano como el principio material de todo lo jurídico. "La justicia

47 V., por ejemplo, Id., E., Anarquía y Personalismo, en Obras, Op. Cit., p. 827.

${ }^{48}$ Véase, sino a KELSEN, H., Qué es justicia, Ariel, Barcelona, 1991, p. 157 y ss)

${ }^{49}$ MOUNIER, E., El Personalismo, Op. cit, pp. 37 y 38

50 “En cuanto teoría (se refiere a la Teoría pura del Derecho) pretende, exclusiva y únicamente, distinguir su objeto. Intenta dar respuesta a la pregunta de qué sea el derecho, y cómo sea; pero no, en cambio, a la pregunta de cómo el derecho deba ser o debe ser hecho. Es ciencia jurídica; no, en cambio, política jurídica” KELSEN, H., Teoría pura del Derecho, Op. Cit., p. 15. 
sin fuerza es impotente, la fuerza sin justicia es tiránica (...) Hay que conjuntar la justicia y la fuerza y para ello hacer que lo justo sea fuerte o que lo fuerte sea justo" 51 .

Por tanto, superando las posiciones iusnaturalistas de tipo esencialista, el siguiente paso para Mounier, en lo que aquí interesa, fue aproximarse a los procesos de categorización que se han seguido (funcionales al paradigma iuspositivista de la teoría general), desde un marco de racionalidad decididamente distinto, que retomase parte de esas otras reivindicaciones modernas que pugnaron por salir en el contexto de la modernidad, pero que fueron postergadas y permanecieron ocultas.

Por tanto, podemos decir que el modelo de normatividad propuesto por el personalismo, sin el ánimo de hacer una revisión exhaustiva, pero sí ubicándonos donde pensamos que se encuentran las claves que lo sintetizan, se apuntala básicamente en tres ideas:

i) En primer lugar, frente a la democracia liberal (plutocrática y parlamentaria), Mounier esboza lo que él insistió en llamar la "democracia personalista". Una democracia basada en "la soberanía del derecho sobre el poder"52. En la que el derecho no nace del poder. Una democracia en la que corresponde al poder, en tanto que elemento extraño al derecho, embarcarse en éste último y transformarse en derecho ${ }^{53}$. Por eso, se opone radicalmente a ese "estatismo", que quiebra el proyecto secularizador que suponía el derecho positivo frente a las tendencias naturalistas, al automatizar las condiciones de validez jurídica del control democrático, ligado a la conexión moderna entre democracia y derechos humanos. "No hay realidad - escribe Mounier -, ni derechos anteriores al Estado que éste deba respetar, ni derecho superior al que éste se deba someter (...). Nada por debajo, nada por encima. Sólo encuentra en sí mismo su límite y su ley" ${ }^{54}$.

ii) Ni la Dogmática Jurídica - con el consiguiente discurso de autonomía y neutralidad - ni la Teoría General de carácter normativista pueden determinar lo que es derecho en cada contexto, ni dar respuesta a las nuevas exigencias que se le plantean, desde las inquietudes teóricas de cada momento

\footnotetext{
${ }^{51}$ Así se pronunciaba el propio Pascal “ (....) La justica sin fuerza es impotente: la fuerza sin justicia es tiránica. A la justicia sin fuerza se le contradice, porque existen siempre malvados; a la fuerza sin justicia se la acusa de tiranía”. Citado por Secretan, Ph., Analogía y Trascendencia. Pascal-Edith Stein-Blondel, Analogía Filosófica. No especial 3, México, 1998, p. 41

52 MOUNIER. E., Manifiesto al servicio del personalismo, Op. cit., p 730.

${ }^{53}$ Ibídem.

${ }^{54}$ Ibid., pp.719-20. Desde el fascismo y las dictaduras del proletariado, hasta el régimen democrático se deslizan en torno a "una realidad (...) que pertenece a la patología social: El desarrollo canceroso del Estado sobre las naciones modernas cualquiera que sea su forma política”. Ibid., p. 721.
} 
histórico, con sus propias singladuras y sus demandas sociales. Porque, por una parte, se acoplan en la idea de validez lógico-formal de las normas jurídicas, esto es, enfoca el problema de la efectividad de el ordenamiento jurídico, desde una perspectiva estrictamente eficientista (el principio de efectividad), sin reparar en el resto de dimensiones de la realidad, incluidas aquéllas que permiten alcanzar precisamente esa efectividad. Al pretender suplantar la realidad, deviene en un sistema solipsista que bloquea cualquier manifestación de exterioridad. Se abre paso así a una concepción puramente funcionalista de los derechos subjetivos ${ }^{55}$, que acarrea la deshumanización de los derechos de las persona, que se conciben, así entendidos, como la mera expresión normativa de ese mismo sistema, y no como la consecuencia necesaria de la juridificación de la idea de dignidad humana; y, por otra, porque reduce el fenómeno jurídico a los esquemas legales, esto es, a las ideas de certeza y de seguridad, que se objetivan en el principio de legalidad. Lo cual se compadece poco con una concepción realista (condiciones para existir/vivir) de los derechos de la persona, pues los reduce a normas legales, ya sea por la vía de la legislación o la vía de una jurisprudencia sometida al exceso formalista (rigorista) de la ley ${ }^{56}$.

iii) El modelo de normatividad propuesto por la filosofía personalista se define en contraposición al concepto kelseniano de persona, en virtud del cual el ser humano es sustituido por la ficción de un sujeto entendido como conjunto de obligaciones, derechos y facultades ${ }^{57}$. El ser humano, en cuanto tal, es desplazado así de la teoría jurídica, en aras de un sujeto pre-existente y desencarnado. El racionalismo kelseniano, por tanto, deshumaniza el derecho. Para este, la Ciencia Jurídica es, o debería ser, solo una que describe normas jurídicas, en pos de una idea abstracta y metafísica de sujeto. Sustituye, en el campo de la relación normativa (relación hecho-efecto), el vinculo necesario propio de la idea de causalidad natural, por el de imputación, que se troca desde entonces en el eje decisivo del juicio normativo, pero que sigue postergando al sujeto de carne y hueso, que seguirá siendo extraño al

\footnotetext{
${ }^{55}$ Podría decirse que la Dogmática ha colmado completamente a la reflexión jurídica, hasta el punto de llegar, incluso, a subordinar funcionalmente el papel de la Teoría General. La posición crítica de Mounier, en este punto, sintoniza bastante con la de Habermas, cuando comentando a Kelsen, este último escribe "la doctrina de los derechos subjetivos pasa el relevo a un funcionalismo sistémico que mediante decisiones metodológicas se desprende de todas las consideraciones de tipo normativo" HABERMAS, J., Factibilidad y Validez. Sobre el derecho y el Estado democrático en términos de la teoría del discurso, Madrid, Trotta, 1998, p. 152.

${ }^{56}$ Este que es pilar fundamental del estado de derecho, en condiciones antidemocráticas - del signo ideológico que sean- se vuelve un instrumento para la denegación de justicia y la absolutización del orden instituido. “ (.....) Rompamos con el formalismo: la libertad no hace la justicia, sino que la sirve”. MOUNIER, E., Revolución personalista y comunitaria, Op. Cit., , p. 187.

57 "La persona física o jurídica que tiene, como su portador, obligaciones jurídicas y derechos subjetivos; es un conjunto de obligaciones jurídicas y derechos subjetivos, cuya unidad se expresa metafóricamente en el concepto de persona. La persona no es más que la personificación de esa unidad”. KELSEN, H., Teoría pura del Derecho, Op. Cit., p. 183.
} 
esquema normativo. Por eso, el pensamiento personalista propone centrar la reflexión jurídica en la persona humana (ser humano vivo y concreto), que viene a erigirse así en la clave para la construcción de una nueva teoría jurídica. De este modo, la Teoría General se segregaría de esa epistemología de tipo positivista, weberiana y analítica (que se pretende así misma como exclusivamente descriptiva ${ }^{58}$ ), al situar a los derechos de la persona, entendidos como condiciones para existir, en el centro de esa nueva visión epistemológica sobre el derecho.

Los derechos subjetivos que radican en el ser humano concreto, en tanto que ser personal con dignidad, están llamados a ocupar así la centralidad de ese nuevo modelo normatividad. Los derechos humanos han estado siempre vinculados a los procesos de reacción contra las desigualdades. Han sido y, siguen siendo, una reacción frente a cualquier tipo de opresión y/o dominación, porque los derechos humanos, que son derechos y que son humanos, son siempre acciones que se dirigen a personas necesitadas. El hecho de que fueran concebidos formalmente bajo el paraguas normativista, no presupone que se deban concebir exclusivamente como derechos individuales ${ }^{59}$, ni tan siquiera como horizontes de posibilidad (visión idealista), sino como "modos de vida" que hagan factible la existencia humana - con dignidad - para todas las personas ${ }^{60}$.

Se puede enfrentar así el idealismo utopista de quienes abogan por una visión absoluta de los derechos humanos, que los reduce a meros horizontes prescriptivos, por otra parte nunca alcanzables, puesto que nuestras acciones son siempre contingentes, como lo son también las instituciones en las que aquellos pretenden objetivarse. Es precisamente aquí cuando arribamos a la conclusión de que obrar conforme a tales derechos (entiéndase humanos) es actuar para paliar sus necesidades en tanto que personas realmente necesitadas. Luego no cabe pensarlos sólo en términos normativos. ¿Acaso no debiera ser al revés? ¿Acaso ese postulado de existencia, vinculado a la praxis humana no debiera servir también como fundamento inmediato para el derecho?. El debe de la norma sólo deviene posible

\footnotetext{
${ }^{58}$ La sumisión de la Teoría jurídica a las exigencias de la Dogmática como discurso científico, está fuertemente asegurada por la función dogmática que desempeña el propio sistema jurídico “(....) La idea es que el discurso del derecho puede traducirse al lenguaje formalizado de la Lógica. De los textos producidos por las autoridades, pueden extraerse las normas y éstas pueden ser convertidas en fórmulas matemáticas". CORREAS, O., Metodología Jurídica. Una Introducción filosófica I, Fontamara, México, $1997, \mathrm{pp} .156$.

${ }^{59}$ Pues los derechos humanos, en aquél entonces, no se podían pensar de otra forma que no fuera a través de los paradigmas en vigor, esto es, desde la doctrina de los derechos subjetivos..

${ }^{60}$ SOLORZANO N., Crítica de la imaginación jurídica. Una mirada desde la epistemología y la historia del derecho moderno y su ciencia, San Luis de Potosí, Universidad Autónoma de San Luis de Potosí, 2007, p. 218
} 
por efecto normativo. Pero, hay un debe más ancho y extenso, un debe ético necesario ${ }^{61}$ : "el deber vivir, que es necesario incluso para poder tener deberes. La forma 'norma jurídica' deviene así superada" 62

En definitiva, puestos a sintetizar, podemos afirmar que lo que llamamos “derecho", desde el realismo crítico personalista, no puede considerarse de manera abstracta, aislado de la acción humana en (con) la que se forja, pues se identifica y conoce a través de la misma; está vinculado a la acción humana a través de la experiencia jurídica que los hombres constituyen y viven. El derecho no puede conocerse si no es desde la praxis concreta e histórica. Es por esto que la filosofía personalista, en este punto, se configura como una propuesta ius-realista, en la medida en que, sin ontologías excluyentes, sitúa la acción humana como la referencia cognoscitiva básica ${ }^{63}$. Por eso se enfrenta al idealismo, para evitar caer en la univocidad de la modernidad, que reduce el derecho a la ley legislada y para reclamar, frente al esencialismo de iusnaturalistas e iuspositivistas, la fuerza de la praxis concreta e histórica; pero no ya solo como divisa epistemológica de la razón jurídica, sino como ética necesaria, que debe permear la acción en derecho. Se supera así el dualismo ontológico entre iusnaturalismo y iuspositivismo, pues ambos se inscriben dentro del idealismo filosófico moderno, ya fuera para construir abstracciones ideales del ser humano o para reducir el derecho a formas trascendentales. La filosofía personalista parte de la persona humana como la referencia antropológica básica. De este modo, el esquema normativo, como modelo epistemológico específico, puede (¿por qué no?) superarse.

Así es, los límites del paradigma iuspositivista de la teoría general se pueden repensar, esta vez, desde un marco de racionalidad distinto (basado en la persona humana viva como categoría decisiva y en la ética del bien común). Lo cual no parece atrevido si admitimos que, siendo la teoría general del derecho una invención también moderna, desde Leibniz, pasando por Savigny y la escuela de la Pandectística alemana ${ }^{64}$ hasta su culminación en Kelsen, esta sencillamente puede ser desbordada por

\footnotetext{
61 "El referente ético básico es la persona humana en sociedad e historia", es la instancia humana básica. V., GAETE, A., Ley natural, ley de humanidad", en Mensaje 432, Santiago de Chile, 1944, p. 441

62 “(...). ¿Revolución científica (Kuhn) también en el derecho y la ciencia jurídica, o simplemente paliativos para las anomalías que no son susceptibles de ser comprendidas en el esquema normativo". SOLORZANO N., Crítica de la imaginación jurídica. Una mirada desde la epistemología y la historia del derecho moderno y su ciencia, Op. Cit., p. 220

63 Una especie de humanismo concreto e histórico que, como bien apunta Antonio Salamanca, es a la vez estructural, materialmente metafísico e intramundano". SALAMANCA, A., El derecho a la revolución, San Luis de Potosí, Comisión Estatal de Derechos humanos, 2006, p. 7.

${ }^{64}$ V. Orestano, Op. cit., pp. 574-577
} 
otros enfoques epistemológicos, también modernos, desde entonces descuidados por esa concepción normativista y legalista del derecho imperante en la teoría general del derecho. ¿Es necesario repensar el derecho? O lo que es lo mismo, ¿es necesario trascender el paradigma normativista como referencia epistemológica decisiva en el derecho? Para la filosofía personalista, sí lo es. Por eso, hablamos de "realismo crítico". Como bien apunta Domenach, la filosofía de Mounier “(...) posiblemente sea la única filosofía contemporánea que conceda un espacio al orden del derecho, entendido este como una mediación entre la fuerza y el amor”65

${ }^{65}$ DOMENACH, J., Emmanuel Mounier, Paris, Editions du Seuil, 1972, p. 88. 


\section{CEFD}

Cuadernos Electrónicos

de Filosofía del Derecho

BIBLIOGRAFIA

BRACHER, K.D., Il Novecento secolo delle ideologie, Bari, Laterza, 1984.

CANDIDE, M., El pensamiento de Emmanuel Mounier (traducción de Ana Ramón Izquierdo), Barcelona, Ediciones Estela, 1969.

CHENU, M.D., Le Saulchoir - Una scuola di teologia (1937), Torino, Marietti, 1982.

CORREAS, O., Metodología jurídica. Una introducción filosófica I, México, Fontanamara, 1997.

RICOEUR, P., “Une philosophie personnaliste”, en Esprit, nº 174, 1950, p. 863.

MELCHIORRE V., "L`interpretazione di Cartessio nell penseiro di Mounier”, en Revista de Filosofia Neo-escolástica, $\mathrm{n}^{\circ}$ 53, 1961.

LEFEBVRE, H., "Du culte de l'Esprit au matérialisme dialectique", en Nouvelle Revue française, diciembre de 1932.

LEGENDRE, P., El amor del censor. Ensayo sobre el orden dogmático, Barcelona, Anagrama, 1979.

MOSSE, G.L., La cultura dell Europa occidentale, Milano, Mondadori, 1986.

MARITAIN, J., Carnet des notes, París, Desclée, 1965.

FERRAJOLI, L, Derecho y razón. Teoría del garantismo penal, Madrid, Trotta, 1995.

GAETE, A., "Ley natural, ley de humanidad”, en Mensaje 432, Santiago de Chile, 1944,

GAUTHIER, F., Triomphe et mort du droit naturel en Révolution, 1789, 1795, 1802, Paris, PUF, 1992.

GILSON, E., Il filosofo e la teologia, Brescia, Morcelliana, 1966.

DOMENACH, J.M., Emmanuel Mounier, Paris, Editions du Seuil, 1972.

HABERMAS, J., Factibilidad y Validez. Sobre el derecho y el Estado democrático en términos de la teoría del discurso, Madrid, Trotta, 1998.

HELLER, A., Una Filosofía de la Historia en fragmentos, Barcelona, Gedisa, 1999.

HEGEL, G.W.F., Fundamentos de la Filosofia del Derecho, Buenos Aires, Siglo Veinte, 1987.

HUGHES, H.S., Coscienza e societá - Storia delle idee in Europa dal 1890 al 1930, Torino, Einaudi, 1967.

JASPERS, K., La Filosofia desde el punto de vista de la existencia, México, FCE, 1953.

KANTOROWIZ, E., "Mysteries of State: An Absolutist Concept and his Late Medieval Origins", en Harvard Theological Review, 48, 1955.

KELSEN, H., Teoría pura del Derecho, UNAM, México, 1979.

KELSEN, H., Qué es justicia, Barcelona, Ariel, 1991.

LACROIX J., "La démocratie et la souveranité du droit”, en Esprit, № 30, Marzo de 1935.

MARCEL, G., Positions et approches concrètes du mystère ontologique, Paris, Desclée de Brouwer, 1935.

MARCEL, G., Ser y tener, Madrid, Caparrós Editores, 1996.

MOUNIER, E., Mounier, E., El Personalismo, Madrid, Ed. Acción Cultural Cristiana, 1990.

MOUNIER, E., Obras Completas, Salamanca, Sígueme, 1992 


\section{Cuadernos Electrónicos}

de Filosofía del Derecho

Manifiesto al Servicio del Personalismo

De la Propiedad Capitalista a la Propiedad Humana

Anarquía y personalismo

MOUNIER. E., Réponse a l'Enquête philosophique sur les conflits actuels d'ideologies. (Texto original mecanografiado), UNESCO PHS/W/68z), 1949.

MONEREO, J.L., "La organización jurídico-económica del capitalismo moderno: El derecho a la economía”, en Ripert, G., Aspectos jurídicos del capitalismo moderno, Granada, Comares, 2001.

ORESTANO, R., Introducción al estudio del derecho romano, Madrid, U Carlos III de Madrid-BOE, 1997.

PALMER, R., The Improvement of Humanity, Education and the French Revolution, Princeton, Princeton University Press, 1985.

SECRETAN, PH., “Analogía y Trascendencia. Pascal-Edith Stein-Blondel”, Analogía Filosófica, No especial 3, 1998.

SOUSA, B., Crítica de la razón indolente. Contra el desperdicio de la experiencia, Bilbao, Desclée de Brouwer, 2003.

SOUSA, B., El milenio huérfano. Ensayos para una nueva cultura política, Madrid, Trotta, 2005,

SOUSA, B., Sociología Jurídica Crítica, Madrid, Trotta, 2009.

TOQUEVILlE, A., Oeuvres Complètes, I, Paris, 1954.

TRIGAUD J.M., Le droit et le futur, Paris, P.U.F., Paris, 1985.

TRIGAUD J.M., Persona ou la justice au double visage, Génova, Studio Editoriale di Cultura, 1990.

SALAMANCA, A., El derecho a la revolución, San Luis de Potosí, Comisión Estatal de Derechos Humanos, 2006

SOlORZANO N., Crítica de la imaginación jurídica. Una mirada desde la epistemología y la historia del derecho moderno y su ciencia, San Luis de Potosí, Universidad Autónoma de San Luis de Potosí, 2007. 